\title{
Introduction: Portuguese Society for Microscopy
}

SPMicros was founded in 1966 as Sociedade Portuguesa de Microscopia and since then has promoted Congresses dedicated to microscopy each year. For many of us this was the place where we delivered our first communications and received feedback by a panel of senior scientists devoted to the promotion of scientific quality; the Society was thus crucial to the rise of more than one generation of microscopists. In 2005 the Society's designation was changed to the "Portuguese Society for Microscopy" aka SPMicros, and incorporated a strong and growing group dedicated to materials science as well as to the life sciences.

The 2012 Congress and the articles gathered in this issue of Microscopy and Microanalysis illustrate the wide variety of subjects being addressed by the members of the Society. This documents the growing awareness of the importance of microscopy for many fields of research and the impact it has for the maintenance and growth of SPMicros activity.

Publication is at the heart of scientific activity and the Society is deeply in debt to Microscopy and Microanalysis and the Microscopy Society of America for providing the opportunity to publish the work of its members. In this way, the tradition of SPMicros as a nursery of sound scientific interest and practice can be maintained.

The Society wishes also to thank all of the members who have contributed to this volume that discloses a collective achievement of an enthusiastic and knowledgeable community of microscopists.

A.P. Alves de Matos

Chairman of the Congress and President of SPMicros 